Quim. Nova, Vol. 34, No. 3, 472-476, 2011

\title{
ESTIMATION OF SURFACE AREA AND PORE VOLUME OF ACTIVATED CARBONS BY METHYLENE BLUE AND IODINE NUMBERS
}

\author{
Cleiton A. Nunes e Mário C. Guerreiro* \\ Departamento de Química, Universidade Federal de Lavras, CP 3037, 37200-000 Lavras - MG, Brasil
}

Recebido em 19/8/10; aceito em 21/10/10; publicado na web em 26/1/11

\begin{abstract}
Data of methylene blue number and iodine number of activated carbons samples were calibrated against the respective surface area, micropore volume and total pore volume using multiple regression. The models obtained from the calibrations were used in predicting these physical properties of a test group of activated carbon samples produced from several raw materials. In all cases, the predicted values were in good agreement with the expected values. The method allows extracting more information from the methylene blue and iodine adsorption studies than normally obtained with this type of material.
\end{abstract}

Keywords: activated carbon; specific surface area; pore volume.

\section{INTRODUCTION}

Activated carbons are porous materials of great importance for several processes. Among the main applications of activated carbons is their use in the adsorption of pollutants in gaseous phase ${ }^{1}$ or liquid phase,${ }^{2}$ gases storage ${ }^{3}$ and as catalysts support. ${ }^{4}$ Porous materials such as activated carbons are usually characterized by several physical parameters such as surface area and pore volume. In the development of these materials it is very important to satisfy such physical properties, because they will directly influence the performance of the material in its application. ${ }^{5}$

The surface areas of activated carbons are usually measured using the Brunauer-Emmett-Teller (BET) method, ${ }^{6}$ which employs the nitrogen adsorption at different pressures at the temperature of liquid nitrogen $(77 \mathrm{~K})$. The surface area according to BET is then determined by the product of the cross-sectional area of the nitrogen molecule, of the Avogadro's number and of the specific monolayer capacity of nitrogen, which is obtained by an equation proposed by BET with further modifications. For the pore volume determination, the procedure more commonly used also uses nitrogen adsorption isotherm data. The total pore volume is estimated from the amount of nitrogen adsorbed at the highest relative pressure and the micropore volume is calculated from the nitrogen adsorption isotherms using the Dubinin-Radushkevich equation. ${ }^{7}$ In spite of these methods being more used and employed as a reference in the surface area and pore volume determination of porous materials, they are time consuming and require the use of expensive equipment.

Additional information about the structure of activated carbons can be obtained by the adsorption characteristics of different adsorbates, such as methylene blue and iodine. Adsorption experiments of these molecules are easy and habitually done to characterize activated carbons with the purpose of obtaining information on the adsorption capacity of the materials. According to the dimensions of the methylene blue molecule, it is mainly adsorbed in mesopores, however, a small portion is also found in larger micropores. In relation to methylene blue, the iodine molecule possesses inferior dimensions which make its penetration in micropores possible. ${ }^{5}$ These charac-

\footnotetext{
*e-mail: guerreiro@dqi.ufla.br
}

teristics confer such molecules the potential for using them as probes in the study of the physical structure of activated carbons. In spite of this, no detailed study has been found concerning the quantitative relationships between methylene blue and iodine numbers and the structural characteristics of the activated carbons.

The aim of this paper is to demonstrate that the surface area, the micropore volume and the total pore volume of activated carbons can be estimated by iodine and methylene blue numbers using multiple regression. The method was developed considering data of several activated carbon samples prepared from different precursors and data extracted from the literature.

\section{EXPERIMENTAL}

\section{Samples}

Data extracted from the literature regarding the surface area, micropore volume, total pore volume, iodine number and methylene blue number of activated carbon samples and experimental data were used in the method development. To test the accuracy of the method, we used experimental and literature data. The literature data were obtained from activated carbons produced from olive-waste cakes, ${ }^{5}$ tree seed husks, ${ }^{8}$ bituminous coal, wood, ${ }^{9}$ Eucalyptus bark, ${ }^{10}$ rubberwood sawdust, ${ }^{11}$ waste newsprint, ${ }^{12}$ sugarcane bagasse, ${ }^{13,14}$ babassu, coconut shells, ${ }^{14}$ sugarcane residues, ${ }^{7}$ olive stones, ${ }^{15}$ petroleum pitch, ${ }^{16}$ shells and fruit pits, ${ }^{17,18}$ fruit seeds ${ }^{18}$ and knitted fabrics, ${ }^{19}$ besides commercial activated carbon. ${ }^{20}$ The experimental data were obtained using activated carbons produced in our laboratory from spent coffee grounds, ${ }^{21}$ bean husks ${ }^{22}$ and a commercial sample.

\section{Methylene blue number (MBN)}

The methylene blue number is defined as the maximum amount of dye adsorbed on $1.0 \mathrm{~g}$ of adsorbent. It is also described in the literature as $q_{e q}{ }^{23} \mathrm{In}$ this assay, $10.0 \mathrm{mg}$ of activated carbon are placed in contact with $10.0 \mathrm{~mL}$ of a methylene blue solution at different concentrations $\left(10,25,50,100,250,500\right.$ and $\left.1000 \mathrm{mg} \mathrm{L}^{-1}\right)$ for $24 \mathrm{~h}$ at room temperature (approximately $25^{\circ} \mathrm{C}$ ). The remaining concentration of methylene blue is analyzed using a UV/Vis spectrophotometer 
(Biosystems SP-2000) at $645 \mathrm{~nm}$.

The amount of methylene blue adsorbed from each solution is calculated by the Equation 1:

$$
q_{e q}\left(m g g^{-1}\right)=\frac{\left(C_{0}-C_{e}\right) \times V}{M}
$$

where $C_{0}\left(\mathrm{mg} \mathrm{L}^{-1}\right)$ is the concentration of the methylene blue solution at starting time $(\mathrm{t}=0), C_{e}\left(\mathrm{mg} \mathrm{L}^{-1}\right)$ is the concentration of the methylene blue solution at equilibrium time, $V(\mathrm{~L})$ is the volume of the solution treated and $M(\mathrm{~g})$ is the mass of the adsorbent.

To determine the methylene blue number for the Langmuir model, a $q_{e q}$ plot is made in function of $C_{e}$. The Langmuir parameters $\left(q_{\max }\right.$ and $K_{L}$ ) are found by a least squares fitting regression.

\section{Iodine number (IN)}

The iodine number is determined according to the ASTM D4607-94 method. The iodine number is defined as the milligrams of iodine adsorbed by $1.0 \mathrm{~g}$ of carbon when the iodine concentration of the filtrate is $0.02 \mathrm{~N}\left(0.02 \mathrm{~mol} \mathrm{~L}^{-1}\right)$. This method is based upon a three-point isotherm. A standard iodine solution is treated with three different weights of activated carbon under specified conditions. The experiment consists of treating the activated carbon sample with $10.0 \mathrm{~mL}$ of $5 \% \mathrm{HCl}$. This mixture is boiled for $30 \mathrm{~s}$ and then cooled. Soon afterwards, $100.0 \mathrm{~mL}$ of $0.1 \mathrm{~N}\left(0.1 \mathrm{~mol} \mathrm{~L}^{-1}\right)$ iodine solution is added to the mixture and stirred for $30 \mathrm{~s}$. The resulting solution is filtered and $50.0 \mathrm{~mL}$ of the filtrate is titrated with $0.1 \mathrm{~N}$ $\left(0.1 \mathrm{~mol} \mathrm{~L}^{-1}\right)$ sodium thiosulfate, using starch as indicator. The iodine amount adsorbed per gram of carbon $(X / M)$ is ploted against the iodine concentration in the filtrate $(C)$, using logarithmic axes. If the residual iodine concentration $(C)$ is not within the range of 0.008 to $0.04 \mathrm{~N}\left(0.008\right.$ to $\left.0.04 \mathrm{~mol} \mathrm{~L}^{-1}\right)$, the whole procedure should be repeated using different carbon masses for each isotherm point. A least squares fitting regression is applied for the three points. The iodine number is the $X / M$ value when the residual concentration $(C)$ is $0.02 \mathrm{~N}\left(0.02 \mathrm{~mol} \mathrm{~L}^{-1}\right)$. The $X / M$ and $C$ values are calculated by the Equations 2 and 3 respectively.

$$
\begin{gathered}
X / M=\left\{\left(N_{1} \times 126.93 \times V_{1}\right)-\left[\left(V_{1}+V_{H c l}\right) / V_{F}\right]\right. \\
\left.\times\left(N_{N_{2} S_{2} \mathrm{O}_{3}} \times 126.93\right) \times V_{\mathrm{Na}_{2} \mathrm{~S}_{2} \mathrm{O}_{3}}\right\} / M_{\mathrm{c}} \\
\mathrm{C}=\left(\mathrm{N}_{\mathrm{Na}_{2} \mathrm{~S}_{2} \mathrm{O}_{3}} \times V_{\mathrm{Na}_{2} \mathrm{~S}_{2} \mathrm{O}_{3}}\right)
\end{gathered}
$$

where $N_{I}$ is the iodine solution normality, $V_{I}$ is the added volume of iodine solution, $V_{H C l}$ is the added volume of $5 \% \mathrm{HCl}, V_{F}$ is the filtrate volume used in titration, $\mathrm{N}_{\mathrm{Na}_{2} \mathrm{~S}_{2} \mathrm{O}_{3}}$ is the sodium thiosulfate solution normality, $\mathrm{V}_{\mathrm{Na}_{2} \mathrm{~S}_{2} \mathrm{O}_{3}}$ is the consumed volume of sodium thiosulfate solution and $M_{C}$ is the mass of activated carbon.

\section{Specific surface area}

Nitrogen adsorption experiments at $77 \mathrm{~K}$ were conducted to determine the specific surface area of the test samples using a Quantachrome Nova-1200 instrument. The samples were outgassed overnight at $180{ }^{\circ} \mathrm{C}$ prior to adsorption measurements. The BET model was applied to fit the nitrogen adsorption isotherms and evaluate the specific surface area of the samples. ${ }^{6}$

\section{Pore volume}

The nitrogen adsorption isotherm data were used for the estimations of the pore volume of the test samples. Total pore volume was estimated from the amount of nitrogen adsorbed at the relative pressure of 0.98 . Micropore volume was calculated from the nitrogen adsorption isotherms using the Dubinin-Radushkevich equation.?

\section{Multiple regression}

The Kennard-Stone algorithm ${ }^{24}$ was used to separate the samples in calibration group and test group. The algorithm selects the samples based on the Euclidean distance. The first two samples selected are the furthest from each other. The following sample is selected by its distance from the previously selected samples. The calibrations were made with different sample amounts in the calibration group. The number of samples used in the calibration was chosen to generate models that show the smallest errors for the test group samples. A least squares fitting was used to obtain the calibration models to make surface area, total pore volume and micropore volume estimations from the methylene blue and iodine numbers. The Matlab software was used for the calculation routines.

\section{RESULTS AND DISCUSSION}

Initially surface graphs were built to check the behavior of the methylene blue and iodine numbers in relation to the surface area, total pore volume and micropore volume of activated carbon samples. The graphs (Figure 1S, supplementary material) were built using data of the samples cited in Experimental section.

In all cases the methylene blue and iodine numbers increased proportionally with the surface area and pore volume, demonstrating that they are interesting probes for the determination of these properties. Indeed, the methylene blue molecule has an area ${ }^{15}$ of $2.08 \mathrm{~nm}^{2}$ and can only enter in large micropores and mesopores. ${ }^{5}$ The iodine molecule is relatively small with an area ${ }^{15}$ of $0.4 \mathrm{~nm}^{2}$ and can enter in the smaller micropores. ${ }^{5}$

\section{Surface area modeling}

To describe the behavior of the methylene blue and iodine numbers in relation to the surface area, a quadratic model was used. For the model development, 27 samples were selected by the Kennard-Stone algorithm from 105 samples and used for calibration. The surface area in the samples varied from 199 to $2105 \mathrm{~m}^{2} \mathrm{~g}^{-1}$. The methylene blue numbers ranged from 0 to $501 \mathrm{mg} \mathrm{g}^{-1}$ and the iodine numbers from 155 to $1670 \mathrm{mg} \mathrm{g}^{-1}$. The surface fit obtained after the modeling (Figure 1) is described by Equation 4.

$$
\begin{aligned}
& S_{\left(m^{2} g^{-1}\right)}=2.28 \times 10^{2}-1.01 \times 10^{-1} M B N+3.00 \times 10^{-1} I N \\
& +1.05 \times 10^{-4} M B N^{2}+2.00 \times 10^{-4} I N^{2}+9.38 \times 10^{-4} M B N I N
\end{aligned}
$$

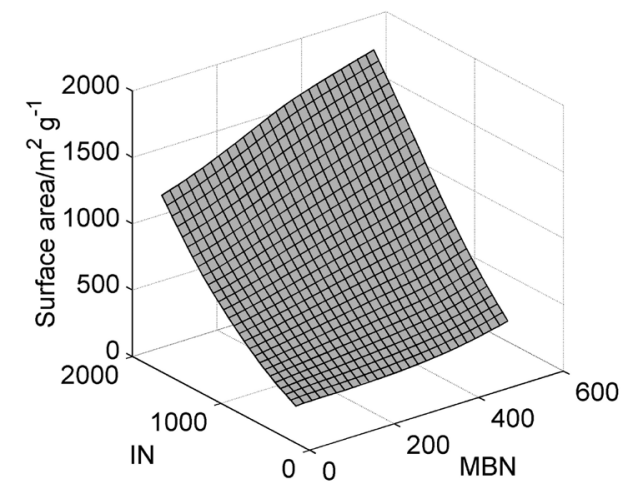

Figure 1. Modeling surface plot for the surface area of activated carbons 
The surface area prediction by this equation was tested for new samples, contemplating data found in the literature and data obtained by us, totaling 78 tested samples. A comparison between the values predicted by Equation 4 and the BET values experimentally obtained are shown in the Figure 2.

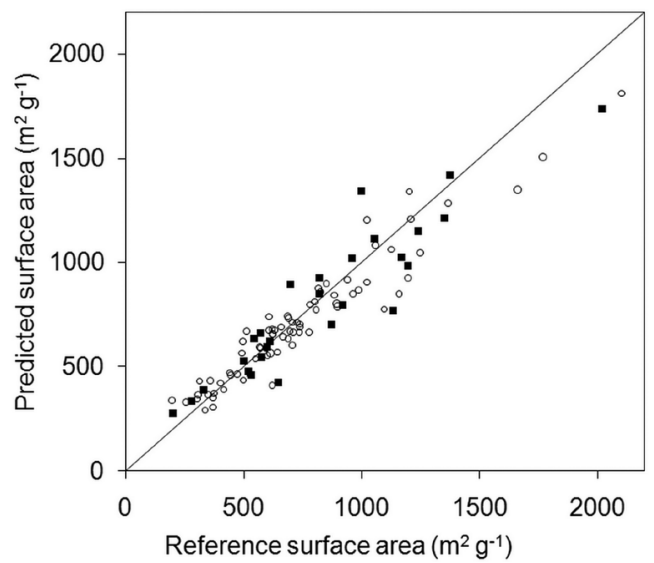

Figure 2. Correlation between measured and predicted surface area of activated carbons ( $\mathbf{\square}$ : calibration set, O: test set)

A good correlation was observed between the values, indicating a good predictive ability of the model. The mean absolute error observed for the test samples was $77.8 \mathrm{~m}^{2} \mathrm{~g}^{-1}$ and the mean relative error was of $11.8 \%$. The statistical parameters of the model are presented in Table 1.

Table 1. ANOVA for surface area model

\begin{tabular}{ccccccc}
\hline & DF & SS & MS & F & p & $\mathrm{R}^{2}$ \\
\hline Model & 5 & 2906950 & 581390 & 25.4 & 0.000 & 0.858 \\
Residual & 21 & 479977 & 22856 & & & \\
Total & 26 & 3386930 & & & & \\
\hline
\end{tabular}

There are reports that the iodine number can provide an approach for the surface area of activated carbons through the relationship between $1 \mathrm{~m}^{2}$ of surface area for each $1 \mathrm{mg}$ of iodine adsorbed. ${ }^{25}$ This consideration was done for the data used in this work, but the obtained errors were significantly higher than that observed when using Equation 4 to estimate the surface area. A least squares fit just considering the iodine number was also made, but the errors were still higher than the errors obtained when using Equation 4. Thus, the iodine number and methylene blue number are important for the surface area estimation of the activated carbons, since the materials possess different pore sizes which can be accessed by the different molecules according to the pore geometry.

\section{Micropore volume modeling}

The micropore volume was also described as a function of the methylene blue and iodine numbers using a quadratic model. The model was built with the help of 50 samples in total, from which 14 were selected for the calibration using the Kennard-Stone algorithm. The calibration range was from 0.05 to $0.99 \mathrm{~cm}^{3} \mathrm{~g}^{-1}$. The methylene blue numbers varied from 2 to $427 \mathrm{mg} \mathrm{g}^{-1}$ and the iodine numbers varied from 195 to $1670 \mathrm{mg} \mathrm{g}^{-1}$. The modeling resulted in the surface fit (Figure 3) and is described by Equation 5:

$$
\begin{aligned}
& V m_{\left(\mathrm{cm}^{3} g^{-1}\right)}=5.60 \times 10^{-2}-1.00 \times 10^{-3} \mathrm{MBN}+1.55 \times 10^{-4} I N \\
& +7.00 \times 10^{-6} \mathrm{MBN} N^{2}+1.00 \times 10^{-7} I N^{2}-1.18 \times 10^{-7} \mathrm{MBN} I N
\end{aligned}
$$

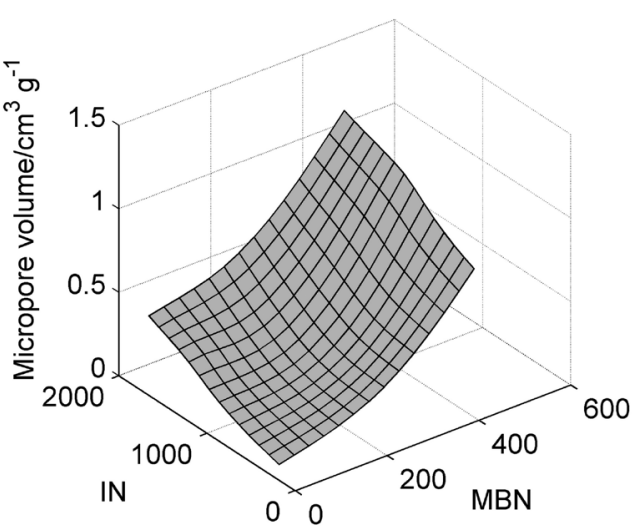

Figure 3. Modeling surface plot for the micropore volume of activated carbons

The applicability of this equation to the micropore volume prediction was evaluated with test samples containing data found in the literature and obtained by us. A total of 36 samples were tested. The graphic comparison (Figure 4) indicates a good predictive capacity of this model. The mean absolute error observed for this test sample group was $0.05 \mathrm{~cm}^{3} \mathrm{~g}^{-1}$ and the mean relative error was $16.4 \%$. The statistical parameters of the model are presented in Table 2.

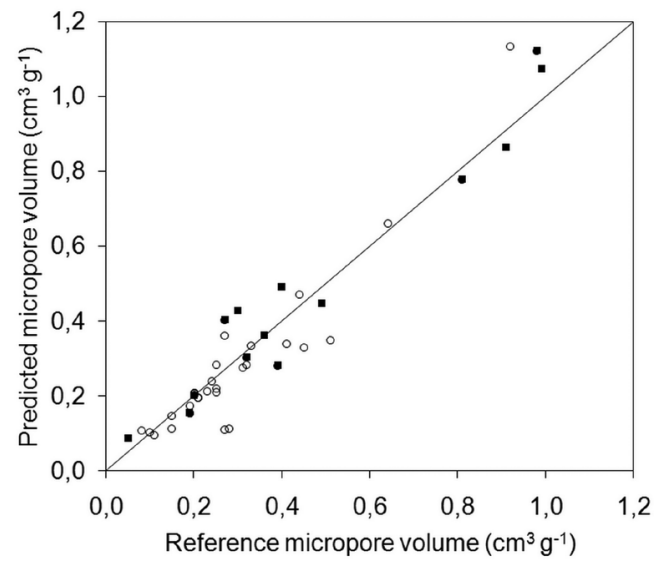

Figure 4. Correlation between measured and predicted micropore volume of activated carbons ( $\mathbf{\square}$ : calibration set, O: test set)

Table 2. ANOVA for micropore volume model

\begin{tabular}{ccccccc}
\hline & DF & SS & MS & F & p & $\mathrm{R}^{2}$ \\
\hline Model & 5 & 1.346 & 0.269 & 26.7 & 0.000 & 0.944 \\
Residual & 8 & 0.081 & 0.010 & & & \\
Total & 13 & 1.426 & & & & \\
\hline
\end{tabular}

The iodine number was also directly correlated with the micropore volume by least squares regression, since the micropores are accessed preferentially by the iodine molecules due to their size. However the obtained errors were higher than those obtained when the methylene blue and iodine numbers were considered. This suggests that the methylene blue has some contribution in the micropore volume prediction, probably due to adsorption in the larger micropores.

\section{Total pore volume modeling}

The relation between the methylene blue and iodine numbers with the total pore volume was established through a linear model. 
The surface was modeled (Figure 5) using 10 samples, selected from 39 by the Kennard-Stone algorithm.

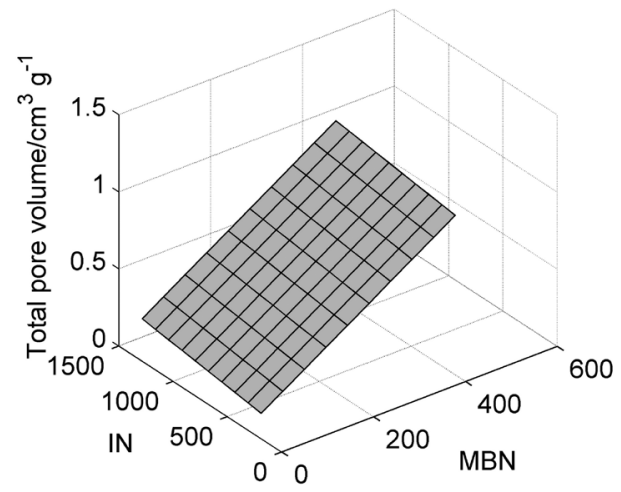

Figure 5. Modeling surface plot for the total pore volume of activated carbons

The calibration range was considered from 0.09 to $1.11 \mathrm{~cm}^{3} \mathrm{~g}^{-1}$. The iodine numbers varied from 195 to $1294 \mathrm{mg} \mathrm{g}^{-1}$ and the methylene blue numbers varied from 2 to $427 \mathrm{mg} \mathrm{g}^{-1}$. The model is described by Equation 6:

$$
V t_{\left(\mathrm{cm}^{3} \mathrm{~g}^{-1}\right)}=1.37 \times 10^{-1}+1.90 \times 10^{-3} \mathrm{MBN}+1.00 \times 10^{-4} \mathrm{IN}
$$

A test group of 29 samples, with data found in the literature and obtained by us, was used to test this equation for the total pore volume prediction. According to the graph showed in Figure 6 there was a good concordance between the predicted values and the reference values. A mean absolute error of $0.04 \mathrm{~cm}^{3} \mathrm{~g}^{-1}$ and a mean relative error of $13.4 \%$ were observed. The statistical parameters of the model are presented in Table 3 .

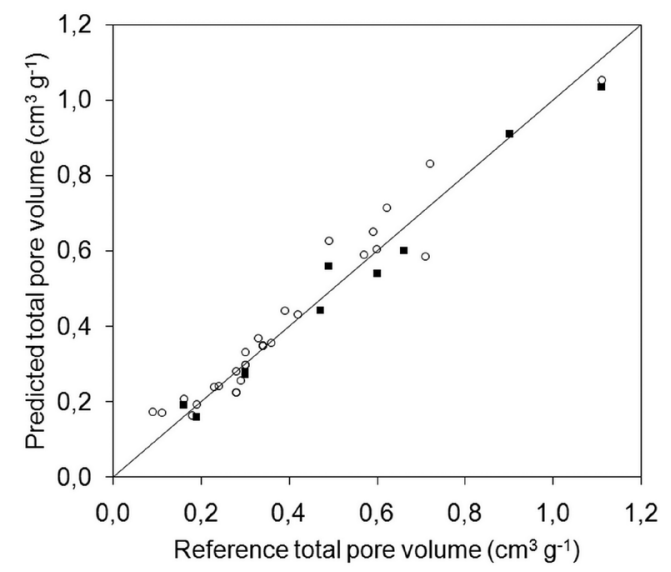

Figure 6. Correlation between measured and predicted total pore volume of activated carbons ( $\mathbf{\square}$ : calibration set, О: test set)

Table 3. ANOVA for total pore volume model

\begin{tabular}{ccccccc}
\hline & DF & SS & MS & F & p & $\mathrm{R}^{2}$ \\
\hline Model & 2 & 0.771 & 0.385 & 173.8 & 0.000 & 0.980 \\
Residual & 7 & 0.016 & 0.002 & & & \\
Total & 9 & 0.786 & & & & \\
\hline
\end{tabular}

\section{CONCLUSIONS}

In this paper we have demonstrated how the iodine number and the methylene blue number can be used to estimate the surface area, the micropore volume and the total pore volume of activated carbon samples through multiple regression. The procedures used in the determination of iodine and methylene blue numbers are relatively cheap and simple and do not require the use of sophisticated equipment. Furthermore, the developed method allows extracting more information from the methylene blue and iodine adsorption studies than normally obtained with this type of material. Although this method does not substitute the proper characterization of the textural properties for activated carbons, it is valuable for laboratories in which the equipment for gas adsorption experiments is not available.

\section{SUPPLEMENTARY MATERIAL}

Surface graphs built to check the behavior of the methylene blue and iodine numbers in relation to the surface area, total pore volume and micropore volume of activated carbon samples are presented in Figure 1S. The graphs were built using data of the samples cited in Experimental section. This material is available gratuitously in http:// quimicanova.sbq.org.br, in PDF file.

Software to compute surface area, micropore volume and total pore volume by methylene blue and iodine numbers using the developed models is also available with the authors. The software runs on Microsoft Windows and requires Macromedia Flash Player installed.

\section{ACKNOWLEDGEMENTS}

The authors acknowledge financial support from Brazilian agencies: Fundação de Amparo à Pesquisa do Estado de Minas Gerais (FAPEMIG), Petróleo Brasileiro S/A (Petrobras), Coordenação de Aperfeiçoamento de Pessoal de Nível Superior (CAPES), Conselho Nacional de Desenvolvimento Científico e Tecnológico (CNPq) and Financiadora de Estudos e Projetos (FINEP). We are also grateful to Prof. Dr. U. Schuchardt for suggestions and corrections on the manuscript.

\section{REFERENCES}

1. Mei, Z. J.; Shen, Z. M.; Zhao, Q. J.; Wang, W. H.; Zhangm, Y. J.; J. Hazard. Mater. 2008, 152, 721.

2. Girods, P.; Dufour, A.; Fierro, V.; Rogaume, Y.; Rogaume, C.; Zoulalian, A.; Celzard, A.; J. Hazard. Mater. 2009, 166, 491.

3. Momen, G.; Hermosilla, G.; Michau, A.; Pons, M.; Firdaouss, M.; Hassouni, K.; Int. J. Hydrogen Energy 2009, 34, 3799.

4. Hung, C. M.; J. Hazard. Mater. 2009, 166, 1314.

5. Baçaoui, A.; Yaacoubi, A.; Dahbi, A.; Bennouna, C.; Luu, R. P. T.; Maldonado-Hodar, F. J.; Rivera-Utrilla, J.; Moreno-Castilla, C.; Carbon 2001, 39, 425 .

6. Brunauer, S.; Emmett, P. H.; Teller, E.; J. Am. Chem. Soc. 1938, 60, 309.

7. Castro, J. B.; Bonelli, P. R.; Cerrella, E. G.; Cukierman, A. L.; Ind. Eng. Chem. Res. 2000, 39, 4166.

8. Warhurst, A. M.; McConnachie, G. L.; Pollard, S. J. T.; Water. Res. 1997, 31, 759.

9. Yu, J. W.; Yang, M.; Lin, T. F.; Guo, Z. H.; Zhang, Y.; Gu, J.; Zhang, S.; Sep. Purif. Technol. 2007, 56, 363.

10. Patnukao, P.; Pavasant, P.; Bioresour. Technol. 2008, 99, 8540.

11. Kumar, B. G. P.; Shivakamy, K.; Miranda, L. R.; Velan, M.; J. Hazard. Mater. 2006, 136, 922.

12. Shimada, M.; Hamabe, H.; Iida, T.; Kawarada, K.; Okayama, T.; J. Porous Mater. 1999, 6, 191.

13. Xia, J.; Noda, K.; Wakao, N.; Kagawa, S.; Nippon Kagaku Kaishi 2000, $4,273$.

14. Jaguaribe, E. F.; Medeiros, L. L.; Barreto, M. C. S.; Araujo, L. P.; Braz. J. Chem. Eng. 2005, 22, 41. 
15. Alaya, M. N.; Hourieh, M. A.; Youssef, A. M.; El-Sejariah, F.; Adsorpt. Sci. Technol. 2000, 18, 27.

16. Chae, J. S.; Ko, K .R.; Jung, C. H.; Rhee, B. S.; Ryu, S. K.; Hwahak Konghak 1993, 31, 99.

17. Fadhil, A. B.; Deyab, M. M.; Arab. J. Sci. Eng. 2008, 33, 175.

18. Mansurov, Z. A.; Zhylybaeva, N. K.; Ualieva, P. S.; Mansurova, R. M.; Chem. Sust. Dev. 2002, 10, 321.

19. Su, C. I.; Wang, C. L.; Fibers Polym. 2007, 8, 477.

20. Gonzalez, J. F.; Encinar, J. M.; Ramiro, A.; Sabio, E.; Ind. Eng. Chem. Res. 2002, 41, 1344.
21. Castro, C. S.; Oliveira, L. C. A.; Guerreiro, M. C.; Catal. Lett. 2009, $133,41$.

22. Oliveira, L. C. A.; Pereira, E.; Guimaraes, I. R.; Vallone, A.; Pereira, M.; Mesquita, J. P.; Sapag, K.; J. Hazard. Mater. 2009, 165, 87.

23. Raposo, F.; De La Rubia, M. A.; Borja, R.; J. Hazard. Mater. 2009, 165, 291.

24. Sales, F.; Callao, M. P.; Ruis, F. X.; Chemom. Intell. Lab. Syst. 1997, 38, 63.

25. Bestani, B.; Benderdouche, N.; Benstaali, B.; Belhakem, M.; Addou, A.; Bioresour. Technol. 2008, 99, 8441. 
ESTIMATION OF SURFACE AREA AND PORE VOLUME OF ACTIVATED CARBONS BY METHYLENE BLUE AND IODINE NUMBERS

Cleiton A. Nunes e Mário C. Guerreiro*

Departamento de Química, Universidade Federal de Lavras, CP 3037, 37200-000 Lavras - MG, Brasil
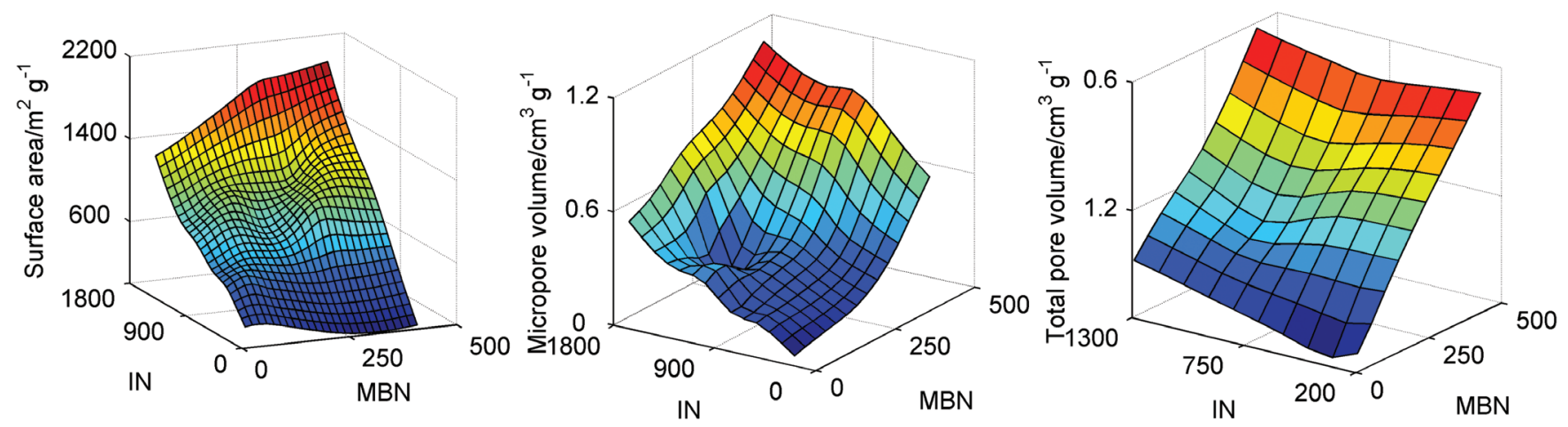

Figure 1S. Surfaces for original data of surface area, micropore volume and total pore volume as a function of the methylene blue and iodine numbers of activated carbons 